\title{
Mechanism Design Theory: The Development in Economics and Management
}

\author{
Xin Zhou \\ School of Management, Jinan University, Guangzhou, China \\ Email:1012935494@qq.com
}

Received 23 March 2016; accepted 24 April 2016; published 27 April 2016

Copyright (c) 2016 by author and Scientific Research Publishing Inc.

This work is licensed under the Creative Commons Attribution International License (CC BY).

http://creativecommons.org/licenses/by/4.0/

c) (i) Open Access

\begin{abstract}
In the last two decades, mechanism design theory is the fastest growing branch in the field of micro-economic with a very broad application space in the practical economy. Also, mechanism design theory brings new study framework for management. Instead of management function theory, mechanism design theory can reveal management activities better. This article will review the development of mechanism design theory in economics and management science, so that it can lay the foundation for future research.
\end{abstract}

\section{Keywords}

\section{Mechanism Design Theory, Economics, Management}

\section{Introduction}

In the 1930s, there had a famous controversy in western economic circles. In this debate called socialism big controversy, liberal economists such as Mises and Hayek argue that socialism is impossible to obtain the information which can maintain the operation of economics effectively. In 1920, Mises denied the possibility that socialism could implement the economic accounting and allocate resources reasonably. He believed that only the monetary-price instruments formed on the production market which in the private ownership society could implement the economic accounting [1]. Hayek further emphasized that the central planning agency was lack of information necessary of price and cost used to allocate resources reasonably. The information only could obtain through the market process itself. Decentralized decision-making which prices were determined by market forces could use the information better than central planning. Thus, from the perspective of resource allocation, 
the market economy was better than central planned economy [2]. Lange and Lerner, who were the representatives of the other side of the debate, argued that people could still take advantage of the market mechanism under socialism, namely implemented the socialist market economy mechanism. In this mechanism, the nation owned means of production, the flow of resources is determined by relationship of supply and demand, enterprises determine the production according to the marginal cost is equal to the price set by central planning agencies. It can be proved that the allocation leaded by the mechanism above is Pareto efficient. Lange believed the central planning authority acquired more knowledge about the economy system than any private entrepreneurs and obtained the correct equilibrium price with a shorter time than successive test series in competition market. Lange proposed a mechanism mode: central planning authority simulated market mechanisms with the way called trial-and-error to determine the price of means of production, so that reached a balance of supply and demand, and ultimately resources could be allocated rationally. Lange stressed that allocation of resources of socialist and capitalist economic was guided by the common principles, and noted that the efficient rules of socialist economic implemented decisions and made decisions, which were similar to actual behavior what entrepreneurs did on a purely competitive market [3]. However, there has a problem in Lange and Lerner's mode: how to motivate companies to complete the tasks assigned by the central planning authorities. Since the marginal cost is private information of enterprises, enterprises in order to make it easier to complete the indicators central planning authorities issued, they have an incentive to hide this information. If the market socialism can't solve the incentive problem, it is impossible to achieve the optimal allocation of resources. This leads to economic mechanism design theory.

Famous American economist, Hurwicz did groundbreaking research about the economic mechanisms theory in the last century. The issues he discussed are: for any economic or social objectives have given, under the decentralized decision-making conditions, for example, free choices, voluntary exchange, incomplete information, whether or how to design an economic mechanism, which can make the personal interests of economic actors in accordance with goals established by designers. From the point of research paths and methods, in the study of traditional economics, the market mechanism has known by which can study what kind of configuration will be leaded. Mechanism design theory puts the social goals as known, trying to find economic mechanism that can achieve the stated social objectives. Specifically, game theory can help solve the problem above. To meet the conditions of each participant constrained, the interaction of tactics chose by participants in the self-interested behavior can put configuration result as same as the expected objectives [4]. This approach laid the theoretical foundation for the future management mechanism design theory.

Mechanism design usually involves two issues: information efficiency and incentive compatibility. Information efficiency is the problem how much information needed to make sure economic mechanism can achieve the stated social objectives. In other words, it is the cost of operation mechanism. Information efficiency demand the mechanism need less information about consumer, producer and other participants of economic activities and lower information cost [5]. Incentive compatibility is a central concept put forward by Hurwitz in 1972, which he defined as, at a given mechanism, truthfully report their private information is dominant strategy equilibrium of participants, this mechanism is incentive-compatible. In this case, even if each participant to develop personal goals in accordance with the principle of self-interest, the objective effect of the mechanism can be implemented to achieve the objectives to be achieved by the designer [6]. Hurwitz summarizes the aforementioned study on mechanism design theory, and published an article called "The Design of Mechanisms for Resource Allocation". Hurwitz proposed a unified framework to analyze and compare various economic mechanisms in this paper, formally laid the foundation for mechanism design theory, and pointed out the most critical issue is how integrate private information and incentive problems, so as to point out the future development direction of mechanism design theory. Later, Hurwitz developed the analytical framework of mechanism design theory, and which is used to analyze and compare a variety of economic systems, including not only all kinds of variants of socialism, including laissez-faire and other conditions [7].

In the beginning of the study, Hurwitz is mainly concentrated in the cost of computing and mechanisms' information, without considering the incentive problem. Incentives theory of team production which Alchian and Demsetz proposed is largely fill this gap. They believe that the essence of business is the "team production". Farm-out among employees can produce business productivity. It is difficult to measure individual employee contributions, so that which can't be paid according to an employee's contribution, thus it may lead to lazy ("free rider") issues. In order to solve this problem, supervision is introduced, who is stimulated by giving residual claimant right [8]. Holmstrom proves that lazy issues can be solved through appropriate incentives me- 
chanism by mathematical model, such as, introducing deposit (The amount equal marginal productivity minus wage), breaking the budget balance, setting up punish or incentive institution for supervisors and employees [9].

Ito researched incentive issues of team production from the opposite perspective. Most of the previous literature in the study, are focusing on how to solve the "inferior" of the work in teams effectively "free rider" behavior. Ito studied how to design mechanisms so that team members can help each other. He was dividing the problem into two parts: First, let employees' income to some extent dependent on the performance of others, inducing people to help each other; the second is the impact to the client's interests if they help each other [10].

In addition, the formation of display principle and development of implementation theory has further deepened the mechanism design theory in the 1970s. Display principle greatly simplifies the analysis of mechanism design theory problems. After Gibbard (1973) proposed a direct display mechanism, Myerson (1979) extended it to a more general Bayesian Nash equilibrium, and pioneered research in the regulation theory and auction theory and others [11]. Display principle does not address the problem of multiple equilibriums, form it Maskin (1977) came out of the implementation theory, the theory has been played an important role present in many research fields including social choice, incomplete contract [12].

\section{Management Mechanism Theory}

Foreign research on management mechanism often explores appropriate management mechanism combined with specific industry or specific issues. Gregory M. parkhurst analysis the disadvantage of the US "Endangered Species Act", "tradable development rights policy", offered to grant compensation mechanism as a dual mechanism, and with the Vickrey-style auction mechanism to achieve compensation pricing of protected areas, and achieve social objectives of species conservation by use policy mechanism rather than "command-control" [13]. Yujing Shen studied the "performance-based contract system of cancer treatment," and found the side effects of incentive policy: as government subsidy and treatment are linked, clinics choose patient with lighter symptoms, rather than patient with severe illness, which was the dominant role of policy-oriented [14]. Buhandiya and Dornier studied decision-making mechanism of UK fiscal/monetary policy; Mitchell uses empirical methods to study the financial mechanism and structural dimensions of detoxification treatment system.

In the 1990s, some Chinese scholars began to study management mechanism design theory, such as Sunshao Rong and Qinsheng Zhang. Sunshao Rong based on the "general principles of management mechanism" that is expected of managers, the principle of relationship between the expected return of objects managed and managers' behavior, research management mechanism design steps and technical issues related. Qinsheng Zhang was based on systems engineering, and group decision-making and mechanism design theory, studied the issues of equal rights and responsibilities, information and incentive, complement and develop the Western theory of mechanism design.

Sunshao Rong and Qinsheng Zhang thought management mechanism is the mechanism of management system operation, the role of managers is to let people managed develop or move toward a certain state. People managed have some kind of spontaneous pursuit, which would be satisfied by achieving the goals what managers made. Which can induce people managed to act in accordance with the manager's will-called "demand principle mechanism”. Designing management system is divided into four steps by them: the tendency analysis (analysis the target pursue of people managed), returns analysis (what managers provided are meet the needs of people managed), state analysis (measure the performance of the people managed), the state and the return connection (the people managed are paid based on performance). Sunshao Rong put forward the concept of "knot", used to describe the relationship between performance and reward, and study all its manifestations of the "knot". [15] But Sunshao Rong's study later deviated from the original intention of the management mechanism, and tracked the behavior control, advocating control human behavior by project, resources, remuneration and other aspects. Xuedong Li defines the concept, features, categories and design step of management mechanisms, thought that the mechanism can be seen as characteristics shown in the system structure and operating. Mechanism design is the requirement of the system of entities in order to realize functions of the system, which itself is a support for system function, and its implementation needs to support by the entity, which is implemented by the system structure and operation design. Zhongyi Sun published a book called "Operational Mechanism of Enterprise Strategic-Theory of Mechanism”, defined the concept, principles of the mechanism and various mechanisms in business operation. Hui Tian explored the mechanism of action and power systems enterprises dynamical system from the perspective of mechanics. 


\section{Conclusion}

Domestic scholars have realized the importance of research management issues in the mechanism level, as lacking of normative research methods, there is no broad impact. So the next direction of our research is to study the enterprise management in mechanism level, to understand management problems in essence, and to solve the problem form the source.

\section{References}

[1] von Mises, L. (1986) Economic Calculation under Socialism. Economic and Social Systems, 1, 6.

[2] Hayek, F.A. (1949) Individualism and Economic Order. Routledge \& Kegan Paul, London.

[3] Lange (1936) On the Economic Theory of Socialism. Review of Economic Studies, 3, 7-28.

[4] Hurwicz, L. (1960) Optimality and Informational Efficiency in Resource Allocation Processes. Vol. 65, Stanford University Press, 8-40.

[5] Tian, G.Q. (2003) Economic Mechanism Theory: Information Efficiency and Incentive Mechanism Design. Economics, 2, 271-308.

[6] Hurwicz, L. (1977) On Informationally Decentralized Systems. Studies in Resource Allocation Processes, 3, 425.

[7] Hurwicz, L. (1973) The Design of Mechanisms for Resource Allocation. American Economic Review, 63, 1-30.

[8] Demsetz, A. and Hong, S. (2003) Production, Information Costs and Economic Organizations. American Economic Review, 5, 15-20.

[9] Holmstrom, B. and Milgrom, P. (1987) Aggregation and Linearity in the Provision of Intertemporal Incentives. Econometrica: Journal of the Econometric Society, 45, 303-328. http://dx.doi.org/10.2307/1913238

[10] Ito, K.I. (1994) Modern Economic Theory. Vol. 7, University of Tokyo Press, 18-40.

[11] Myerson, R.B. (1979) Incentive Compatibility and the Bargaining Problem. Econometrica: Journal of the Econometric Society, 47, 61-73. http://dx.doi.org/10.2307/1912346

[12] Equilibrium, M.E.N. (1977) Welfare 0ptmalty. Mathematics of Operations Research, 78, 45-60.

[13] Shogren, J.F., Parkhurst, G.M. and Settle, C. (2003) Integrating Economics and Ecology to Protect Nature on Private Lands: Models, Methods, and Mindsets. Environmental Science \& Policy, 6, 233-242. http://dx.doi.org/10.1016/S1462-9011(03)00041-8

[14] Shen, Y. (2003) Selection Incentives in a Performance-Based Contracting System. Health Services Research, 38, 535552. http://dx.doi.org/10.1111/1475-6773.00132

[15] Sun, S.R. and Zhu, J.S. (1995) Management Mechanism Design Theory. Systems Engineering Theory and Practice, 15, 50-55. 